\title{
Kinetic Study of Organic Dye Degradation Using ZnO Particles with Different Morphologies as a Photocatalyst
}

\author{
Swee-Yong Pung, Wen-Pei Lee, and Azizan Aziz \\ School of Materials and Mineral Resources Engineering, Universiti Sains Malaysia, Seri Ampangan, 14300 Nibong Tebal, \\ Pulau Pinang, Malaysia \\ Correspondence should be addressed to Swee-Yong Pung, sypung@eng.usm.my
}

Received 4 November 2011; Revised 15 February 2012; Accepted 20 February 2012

Academic Editor: Wei-Yin Sun

Copyright ( $(2012$ Swee-Yong Pung et al. This is an open access article distributed under the Creative Commons Attribution License, which permits unrestricted use, distribution, and reproduction in any medium, provided the original work is properly cited.

Zinc oxide $(\mathrm{ZnO})$ particles were successfully synthesized via sol-gel approach using zinc acetate dihydrate $\left(\mathrm{Zn}\left(\mathrm{CH}_{3} \mathrm{COO}\right)_{2} \cdot 2 \mathrm{H}_{2} \mathrm{O}\right)$ and ammonia $\left(\mathrm{NH}_{4} \mathrm{OH}\right)$ solution as precursors. By adjusting the reaction parameters such as amount of ammonia and reaction time as well as complexing agent aluminium sulphate $\mathrm{Al}_{2}\left(\mathrm{SO}_{4}\right)_{3}, \mathrm{ZnO}$ particles with different morphologies, that is, rodlike, ricelike and disklike could be synthesized. The effectiveness of $\mathrm{ZnO}$ particles with different morphologies (rodlike, ricelike and disklike) on the photocatalytic activity has been studied. The results showed that rodlike $\mathrm{ZnO}$ particles were the most effective in degrading the Rhodamine B (RhB) solution under the illumination of ultraviolet (UV) light. The rate constant was found to be first order, with rodlike particles the highest $\left(0.06329 \mathrm{~min}^{-1}\right)$, followed by rice-like $\mathrm{ZnO}$ particles $\left(0.0431 \mathrm{~min}^{-1}\right)$ and disk-like ZnO particles $\left(0.02448 \mathrm{~min}^{-1}\right)$.

\section{Introduction}

Photocatalysis of organic compounds such as methyl green and Rhodamine $\mathrm{B}(\mathrm{RhB})$ in water is receiving attention due to the severe ecological impact of various industrial and agricultural pollutants $[1,2]$. Photocatalytic activities can be classified into homogeneous or heterogeneous reactions depending on the nature of their reactants and materials (semiconductors). Particularly, heterogeneous photocatalytic study using semiconductor materials such as $\mathrm{TiO}_{2}$ and $\mathrm{ZnO}$, through particulate systems, has become an exciting and rapidly growing area of research in the last few years mainly due to the relatively simple photodecomposition of organic pollutant molecules into less harmful compounds [3-7].

$\mathrm{ZnO}$ has been chosen as photocatalyst because of its high catalytic efficiency, low cost, large bandgap $(3.37 \mathrm{eV})$, and nontoxic nature. In fact, it has been shown to be more effective than $\mathrm{TiO}_{2}$ as photocatalysts in recent studies $[8,9]$. The effect of various parameters such as UV light intensity [3], initial dye concentration [3, 10, 11], $\mathrm{pH}$ of the medium [10], amount of photocatalyst [3, 11], doping $[4,12]$, and temperature [13] were reported. However, the effect of morphology of $\mathrm{ZnO}$ particles remains as a field to be explored.

The morphology of $\mathrm{ZnO}$ particles can be easily manipulated by tailoring the reaction parameters. By adjusting the temperature, concentration of solution, $\mathrm{pH}$, heating duration, and complexing agent, different morphology of $\mathrm{ZnO}$ particles such as nanoprisms [14], nanorods [15], nanoflowers [16], nanosheets [17], and nanodisks [18] could be synthesized, respectively. Different morphology of $\mathrm{ZnO}$ particles have different exposed crystal planes. For example, the main exposed crystal plane of $\mathrm{ZnO}$ nanodisks is (002) with atomic planar density of $1.1 \times 10^{19}$ atoms $/ \mathrm{m}^{2}$. The plane is either negatively charge $(-\mathrm{O})$ terminated or positively charge $(-\mathrm{Zn})$ terminated. On the contrary, the main exposed crystal plane of $\mathrm{ZnO}$ nanorods is $\{100\}$ with atomic planar density of $5.9 \times 10^{18}$ atoms $/ \mathrm{m}^{2}$. These crystal planes are composed of alternating layer of $\mathrm{Zn}$ and $\mathrm{O}$ atoms. Since the photocatalytic activity has occurred on the active surface of particles, controllable design of $\mathrm{ZnO}$ particles with various morphologies is the focus of current research.

In this study, $\mathrm{ZnO}$ particles were synthesized by sol-gel method using zinc acetate dihydrate and ammonia solution as precursors. Systematic study on the effect of reaction 


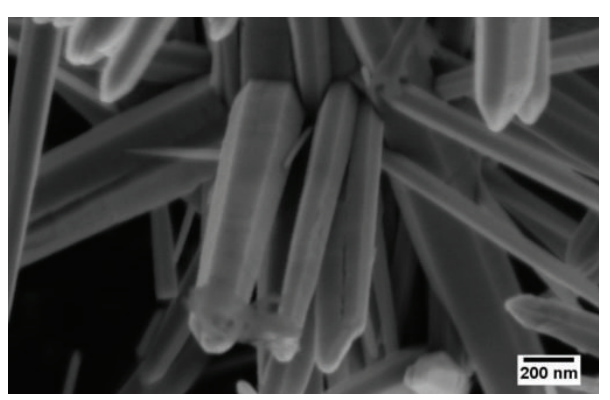

(a)

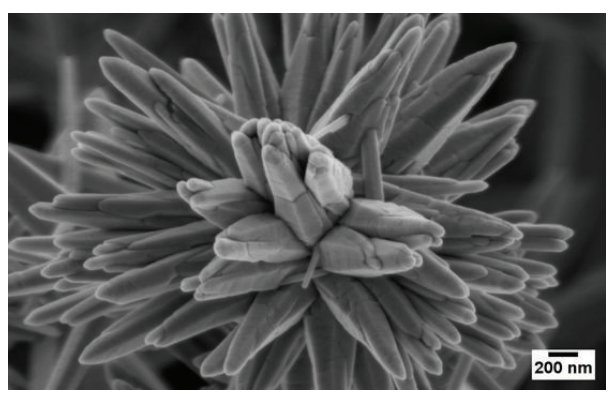

(b)

FIGURE 1: SEM image of (a) rodlike and (b) flower-like $\mathrm{ZnO}$ particles.

parameters such as amount of ammonia, reaction time, and addition of complexing agent on the growth of $\mathrm{ZnO}$ particles was carried out. By controlling the process window, several desired morphologies such as ricelike, rodlike, and disklike particles were synthesized. A better insight on the possible growth mechanism of these morphologies was gained. The photocatalytic activity of $\mathrm{ZnO}$ particles was evaluated by illuminating the mixture of $\mathrm{ZnO}$ particles and $\mathrm{RhB}$ with ultraviolet (UV). RhB was chosen as model pollutant because it is one of the most widely used xanthene dyes in the textile industry and has become a common organic pollutant. The efficiency of $\mathrm{ZnO}$ particles with different morphologies on the degradation of RhB will be discussed. The study of RhB degradation and understanding its reaction kinetics helped to consider actual effluent for the photocatalytic activities, in view of its complexity in containing diverse types of dyes and other chemicals.

\section{Experimental Details}

Zinc acetate dihydrate was used as the source of zinc ion whereas ammonia was used as the source of hydroxide ion. Different morphologies of $\mathrm{ZnO}$ particles were obtained by varying the amount of ammonia, reaction time, and addition of aluminium sulphate as complexing agent. Then, the synthesized $\mathrm{ZnO}$ particles were sent for characterization such as scanning electron microscopy (SEM, FESEM, Zeiss Supra 35VP), X-ray diffraction (XRD, Bruker Advanced Xray Solution D8 Diffractometer $\left.\left(\mathrm{Cu} \mathrm{K}_{\alpha}, \lambda=0.154 \mathrm{~nm}\right)\right)$, and photoluminescence measurement (PL, $\mathrm{N}_{2}$ laser excitation source, $337 \mathrm{~nm}$, pulse rate $20 \mathrm{~Hz}$ ). Lastly, the photocatalytic study using $\mathrm{ZnO}$ particles with different morphologies was conducted. The compound selected to be degraded in this project was Rhodamine $(\mathrm{RhB})$. The photocatalytic activity of $\mathrm{ZnO}$ particles was achieved by illuminating mixture of $10 \mathrm{mg} \mathrm{ZnO}$ particles and $20 \mathrm{~mL} \mathrm{RhB}\left(1 \times 10^{-5} \mathrm{M}\right)$ with ultraviolet (360 watts UV lamps, Phillips, $254 \mathrm{~nm}$ ). Then, the degraded RhB solution was sent for UV-Vis analysis (UV-Vis spectrophotometer, cary 5,553 nm) to measure the photodegradation efficiency of $\mathrm{ZnO}$ particles at room temperature.

\section{Results and Discussion}

3.1. Effect of Reaction Parameters on the Growth of $\mathrm{ZnO}$ Particles.

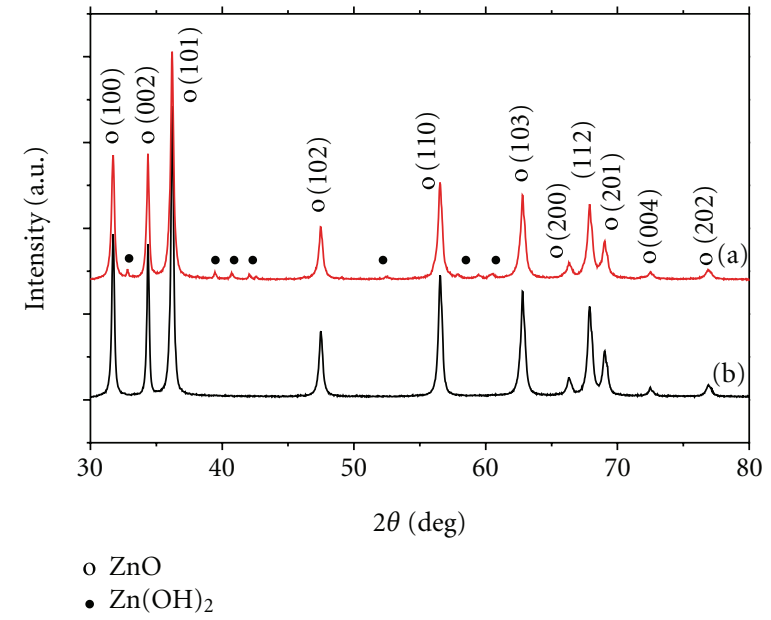

FIGURE 2: XRD diffractogram of (a) rodlike and (b) flower-like particles.

3.1.1. Effect of Reaction Time. To study the evolution of rodlike morphology, experiments were carried out using $2.0 \mathrm{~mL}$ of $\mathrm{NH}_{4} \mathrm{OH}$ and reacted for $1 \mathrm{~h}$ and $4 \mathrm{~h}$. When reacted for $1 \mathrm{~h}$, as shown in Figure 1(a), rodlike particles were formed. The rodlike structures had a diameter of $155.0 \pm$ $25.29 \mathrm{~nm}$ and a length of $1134.7 \pm 120.78 \mathrm{~nm}$. The aspect ratio of rodlike particles was 7.5 . When it was prolonged to $4 \mathrm{~h}$, an individual flower-like structure composed of nanorods was obtained as shown in Figure 1(b). The diameter of the petals varied from the base to the tips, showing that the petals had sharpened tips with the wider bases that were connected to each other through their wider bases. The diameters of these petals at their tips and bases were between $101.8 \pm 18.84 \mathrm{~nm}$ and $196.7 \pm 67.36 \mathrm{~nm}$, respectively, and the lengths of these petals were $1172.6 \pm 370.38 \mathrm{~nm}$. The EDX analysis on both rodlike and flower-like particles indicates that the atomic percentages of $\mathrm{Zn}$ and $\mathrm{O}$ have a ratio approximately $1: 1$. No evidence of impurities was found.

Figures 2(a) and 2(b) show the X-ray diffraction (XRD) patterns for rodlike and flower-like particles. Both XRD patterns show peaks at $31.7^{\circ}, 34.4^{\circ}, 36.2^{\circ}, 47.5^{\circ}, 56.5^{\circ}, 62.7^{\circ}$, $66.3^{\circ}, 67.8^{\circ}, 69.1^{\circ}, 72.5^{\circ}$, and $79.9^{\circ}$, which correspond to (100), (002), (101), (102), (110), (103), (200), (112), (210), (004), and (202) crystal planes of hexagonal $\mathrm{ZnO}$ (JCPDS card no. 36-1451). Extra peaks marked with black dots at $32.9^{\circ}, 39.5^{\circ}, 40.8^{\circ}, 42.2^{\circ}, 52.5^{\circ}, 59.6^{\circ}$ and $60.7^{\circ}$ are observed 
for rodlike particles as shown in Figure 2(a). These peaks are indexed to $\mathrm{Zn}(\mathrm{OH})_{2}$ (JCPDS card no. 38-0385). The result indicates that $\mathrm{Zn}(\mathrm{OH})_{2}$ was present in rodlike particles. This could be due to a short reaction time. In fact, a longer reaction time was needed for $\mathrm{Zn}(\mathrm{OH})_{2}$ to be hydrolyzed to $\mathrm{Zn}(\mathrm{OH})_{4}{ }^{2-}$ complex ions before $\mathrm{ZnO}$ nuclei formed. No other diffraction peaks were found for flower-like particles as shown in Figure 2(b).

The formation of $\mathrm{ZnO}$ particles on the above study is proposed as follows $[19,20]$. When zinc acetate dihydrate, $\mathrm{Zn}\left(\mathrm{CH}_{3} \mathrm{COO}\right)_{2}$ was dissolved in water, it dissociated into zinc ion, $\mathrm{Zn}^{2+}$, and acetate ion, $\mathrm{CH}_{3} \mathrm{COO}^{-}$, as shown in (1). Then, $\mathrm{CH}_{3} \mathrm{COO}^{-}$ions were hydrolyzed and released $\mathrm{OH}^{-}$ion as shown in (2). When ammonia solution was added, $\mathrm{NH}_{4} \mathrm{OH}$ was dissolved in the water and hydrolyzed to ammonium ion, $\mathrm{NH}_{4}^{+}$, and hydroxide ion, $\mathrm{OH}^{-}$, as shown in (3):

$$
\begin{gathered}
\mathrm{Zn}\left(\mathrm{CH}_{3} \mathrm{COO}\right)_{2} \longrightarrow 2 \mathrm{CH}_{3} \mathrm{COO}^{-}+\mathrm{Zn}^{2+} \\
\mathrm{CH}_{3 \mathrm{COO}^{-}+\mathrm{H}_{2} \mathrm{O}} \longrightarrow \mathrm{OH}^{-}+\mathrm{CH}_{3} \mathrm{COOH} \\
\mathrm{NH}_{3}+\mathrm{H}_{2} \mathrm{O} \longleftrightarrow \mathrm{NH}_{4}^{+}+\mathrm{OH}^{-}
\end{gathered}
$$

Subsequently, tetraaminezincate ion, $\mathrm{Zn}\left(\mathrm{NH}_{3}\right)_{4}{ }^{2+}$, zinc hydroxide, $\mathrm{Zn}(\mathrm{OH})_{2}$, or tetrahydroxozincate ion, $\mathrm{Zn}(\mathrm{OH})_{4}{ }^{2-}$ may be formed. The $\mathrm{OH}^{-}$ion may react with $\mathrm{Zn}^{2+}$ ion to form $\mathrm{Zn}(\mathrm{OH})_{2}$ white precipitate as shown in (4) or $\mathrm{Zn}(\mathrm{OH})_{4}{ }^{2-}$ complex ion as suggested in (5). $\mathrm{Zn}^{2+}$ ions may also react with $\mathrm{NH}_{4}{ }^{+}$ion to form $\left[\mathrm{Zn}\left(\mathrm{NH}_{3}\right)_{4}\right]^{2+}$ complex ion as shown in (6). Both $\mathrm{Zn}(\mathrm{OH})_{4}{ }^{2-}$ complex ion and $\left[\mathrm{Zn}\left(\mathrm{NH}_{3}\right)_{4}\right]^{2+}$ complex ion could be served as growth units for $\mathrm{ZnO}$ nuclei,

$$
\begin{gathered}
\mathrm{Zn}^{2+}+2 \mathrm{OH}^{-} \longrightarrow \mathrm{Zn}(\mathrm{OH})_{2} \\
\mathrm{Zn}^{2+}+4 \mathrm{OH}^{-} \longrightarrow \mathrm{Zn}(\mathrm{OH})_{4}{ }^{2-} \\
\mathrm{Zn}^{2+}+4 \mathrm{NH}_{4}{ }^{+} \longrightarrow \mathrm{Zn}\left(\mathrm{NH}_{3}\right)_{4}{ }^{2+}
\end{gathered}
$$

Finally, $\mathrm{ZnO}$ nuclei was crystallized as a result of the reaction of $\left[\mathrm{Zn}\left(\mathrm{NH}_{3}\right)_{4}\right]^{2+}$ complex ion and $\mathrm{OH}^{-}$ion as shown in (7). $\mathrm{Zn}(\mathrm{OH})_{4}{ }^{2-}$ complex ion could be transformed into $\mathrm{ZnO}$ nuclei as proposed in (8). $\mathrm{ZnO}$ nuclei could also be formed from $\mathrm{Zn}(\mathrm{OH})_{2}$ but only after the formation of $\mathrm{Zn}(\mathrm{OH})_{4}{ }^{2-}$ growth unit by reacting with $\mathrm{OH}^{-}$ion as shown in (9):

$$
\begin{gathered}
\mathrm{Zn}\left(\mathrm{NH}_{3}\right)_{4}{ }^{2+}+2 \mathrm{OH}^{-} \longrightarrow \mathrm{ZnO}+4 \mathrm{NH}_{3}+\mathrm{H}_{2} \mathrm{O} \\
\mathrm{Zn}(\mathrm{OH})_{4}{ }^{2-} \longrightarrow \mathrm{ZnO}+\mathrm{H}_{2} \mathrm{O}+2 \mathrm{OH}^{-} \\
\mathrm{Zn}(\mathrm{OH})_{2}+2 \mathrm{OH}^{-} \longrightarrow \mathrm{Zn}(\mathrm{OH})_{4}{ }^{2-}
\end{gathered}
$$

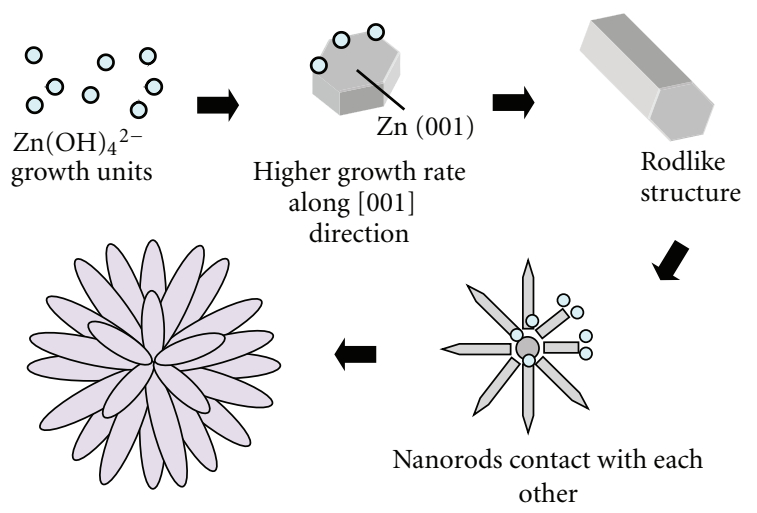

Flower-like structure

FIGURE 3: Schematic diagram of formation of rodlike and flowerlike $\mathrm{ZnO}$ particles.

The negative-charged $\mathrm{Zn}(\mathrm{OH})_{4}{ }^{2-}$ complex ions were preferentially adsorbed onto the positive-charged (001) Zn plane and subsequently dehydrated and entered into the crystal lattice. The growth rate of the (001) plane was greatly favored. The more rapid the growth rate, the quicker the disappearance of the basal plane. Thus, rodlike $\mathrm{ZnO}$ particles with elongated $c$-axis surrounded by six $\{100\}$ planes was formed. While the growth rates of some $\{101\}$ planes were relatively smaller than those of (001), they remained to form needle-like tips.

Similar observation, that is, formation of flower-like particles from nanorods with prolong reaction time has been reported by Jiang et al. [21]. The proposed growth mechanism is illustrated in Figure 3. Nanorods grow and contact with each other during the synthesis process. Secondary nucleation occurs on the surface of some of the nanorods, resulting in formation of flower-like particles.

3.1.2. Effect of Ammonia Concentration. As shown by (5) and (6), varying the ammonia concentration could affect the concentration $\mathrm{ZnO}(\mathrm{OH})_{4}{ }^{2-}$. By reducing the volume of $\mathrm{NH}_{4} \mathrm{OH}$, that is, from $2.0 \mathrm{~mL}$ to $1.5 \mathrm{~mL}$, conelike and ricelike nanoparticles were syntheszied instead of rodlike particles. Figure 4(a) shows conelike particles with a diameter of $146.8 \pm 21.20 \mathrm{~nm}$ and a length of $216.3 \pm 26.30 \mathrm{~nm}$ at the earlier stage of particles growth $(0.5 \mathrm{~h})$. As the reaction time was prolonged to $2 \mathrm{~h}$, the particles became ricelike as shown in Figure 4 (b). The ricelike particle looked like a twincone structure, composed of two cones with round bottom connected to each other. This can be identified with the wellresolved slit observed in the middle of the particles. The EDX analysis indicates that the atomic percentages of $\mathrm{Zn}$ and $\mathrm{O}$ had a ratio approximately $1: 1$. No evidence of other impurities was found.

Figure 5 shows the X-ray diffraction (XRD) patterns of conelike particles and ricelike particles. The XRD pattern of conelike particles shows peaks correspond to crystal planes of hexagonal $\mathrm{ZnO}$ (JCPDS card no. 36-1451). Extra peaks marked with black dots are indexed to $\mathrm{Zn}(\mathrm{OH})_{2}$ (JCPDS card no. 38-0385). This shows that $\mathrm{Zn}(\mathrm{OH})_{2}$ was present in conelike particles attributed to short reaction time that is 


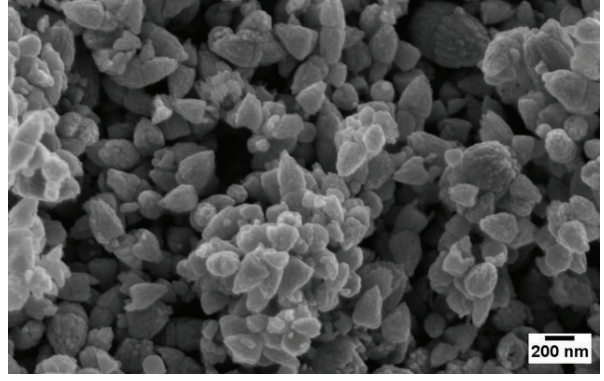

(a)

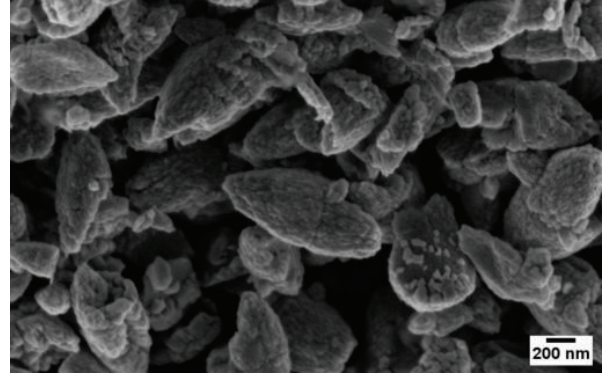

(b)

Figure 4: SEM image of (a) conelike particles and (b) ricelike particles.

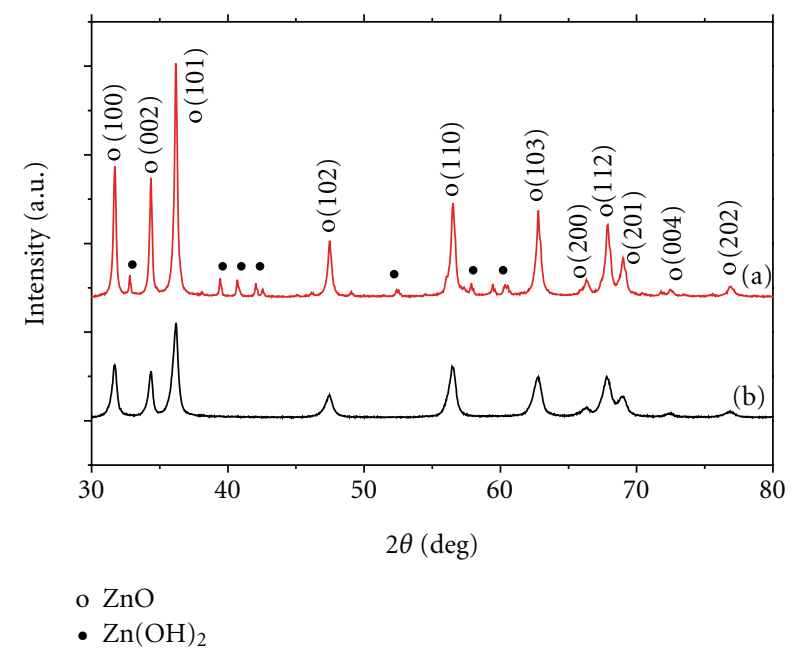

FIGURE 5: XRD diffractogram of (a) conelike particles and (b) ricelike particles.

$0.5 \mathrm{~h}$. Meanwhile, no peaks of $\mathrm{Zn}(\mathrm{OH})_{2}$ was observed from the XRD pattern of ricelike particles as shown in Figure 5(b). Ricelike particles were obtained when reacted for $2 \mathrm{~h}$. The presence of $\mathrm{Zn}(\mathrm{OH})_{2}$ was eliminated by prolonging the reaction time. This result is consistent with the observation in Section 3.1.1, that is, longer reaction time is required to transform $\mathrm{Zn}(\mathrm{OH})_{2}$ to $\mathrm{Zn}(\mathrm{OH})_{4}{ }^{2-}$ complex ions in order to produce $\mathrm{ZnO}$ nuclei.

The conelike $\mathrm{ZnO}$ particles were formed due to uneven and multidimensional growth of $\mathrm{ZnO}$ particles. The surface of the round bottom of each cone, that is, (002), could comprise the negatively charge $\mathrm{O}^{2-}$-terminated plane or the polar positively charge $\mathrm{Zn}^{2+}$-terminated planes. Thus, a one-dimensional polar field was established from the $\mathrm{O}^{2-}$ terminated to $\mathrm{Zn}^{2+}$ terminated. According to the polar-fieldinduced assembly concept, two single cones with opposite polar field directions assembled spontaneously during the crystal growth process to counterbalance the polar fields. As a result, this led to the formation of the twin-cone structures or known as ricelike structure. The schematic diagram of conelike and ricelike particles formation is suggested in Figure 6.

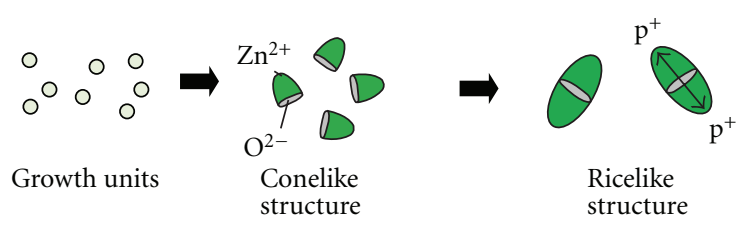

FIGURE 6: Schematic diagram of formation of conelike and ricelike $\mathrm{ZnO}$ particles.

3.1.3. Effect of Complexing Agent. Without complexing agent of $\mathrm{Al}_{2}\left(\mathrm{SO}_{4}\right)_{3}$, conelike structures were obtained from the solution as shown in Figure 4(a). However, addition of $\mathrm{Al}_{2}\left(\mathrm{SO}_{4}\right)_{3}$ into the precursor solution produced disklike particles instead of conelike particles as shown in Figure 7(a). The nanodisks had a thickness of $13.5 \pm 1.03 \mathrm{~nm}$. Besides, some of the disks had a hole in the middle, forming $\mathrm{ZnO}$ nanorings. As shown in Figure 7(b), the EDX spectrum of disklike particles indicates that it composed of $\mathrm{Zn}, \mathrm{O}, \mathrm{Al}$, and $\mathrm{S}$ elements. The $\mathrm{Al}$ and $\mathrm{S}$ elements were from the addition of aluminium sulphate $\mathrm{Al}_{2}\left(\mathrm{SO}_{4}\right)_{3}$ as complexing agent. Figure 8 shows the X-ray diffraction (XRD) patterns for disklike particles. The XRD patterns show peaks correspond to crystal planes of hexagonal ZnO (JCPDS card no. 36-1451). Extra peaks marked with asterisks are assigned to $\mathrm{Al}_{2} \mathrm{O}_{3}$, which could be attributed to precipitation and oxidation of $\mathrm{Al}^{3+}$ ions that originated from aluminium sulphate, $\mathrm{Al}_{2}\left(\mathrm{SO}_{4}\right)_{3}$.

As proposed by $\mathrm{Ye}$ et al., the growth of disklike $\mathrm{ZnO}$ particles was mediated by the adsorption of aluminate ion, $\mathrm{Al}(\mathrm{OH})_{4}{ }^{-}$[22]. The $\mathrm{Al}(\mathrm{OH})_{4}{ }^{-}$ions were obtained as a result of reaction between $\mathrm{Al}_{2}\left(\mathrm{SO}_{4}\right)_{3}$ and $\mathrm{NH}_{4} \mathrm{OH}$. The $\mathrm{Al}(\mathrm{OH})_{4}{ }^{-}$ ions were presumed to be bonded to the positively charged $\mathrm{Zn}^{2+}$-terminated (0001) surface of $\mathrm{ZnO}$ and suppressed the growth along the [0001] direction. This allowed the lateral growth to occur. Disklike $\mathrm{ZnO}$ particles were thus formed. On the contrary, the formation of ringlike $\mathrm{ZnO}$ particles was suggested due to the dissolution of $\mathrm{ZnO}$ [18]. As time passed by, there was a depletion of $\mathrm{OH}^{-}$ion in the solution. Therefore, there would be a decrease in $\mathrm{Zn}(\mathrm{OH})_{4}{ }^{2-}$ growth units. To compensate the decrease in $\mathrm{Zn}(\mathrm{OH})_{4}{ }^{2-}$ complex ions, the equilibrium of (8) was shifted to the left, which resulted in the dissolution of $\mathrm{ZnO}$. The (001) plane was removed instead of nonpolar $\{100\}$ plane because 


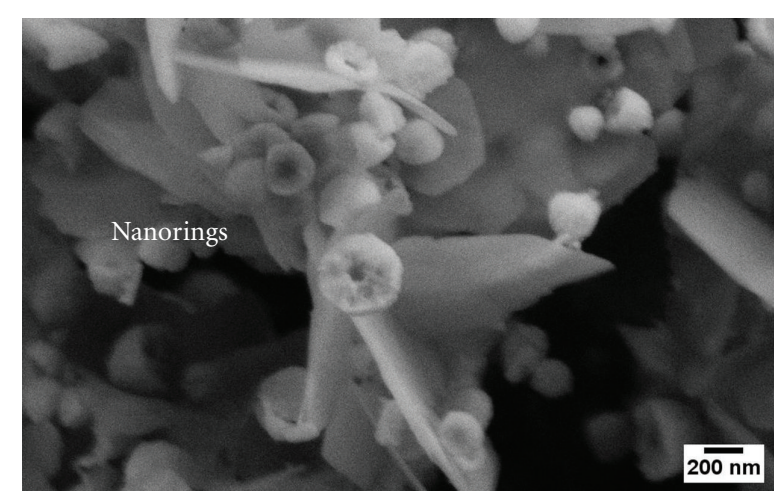

(a)

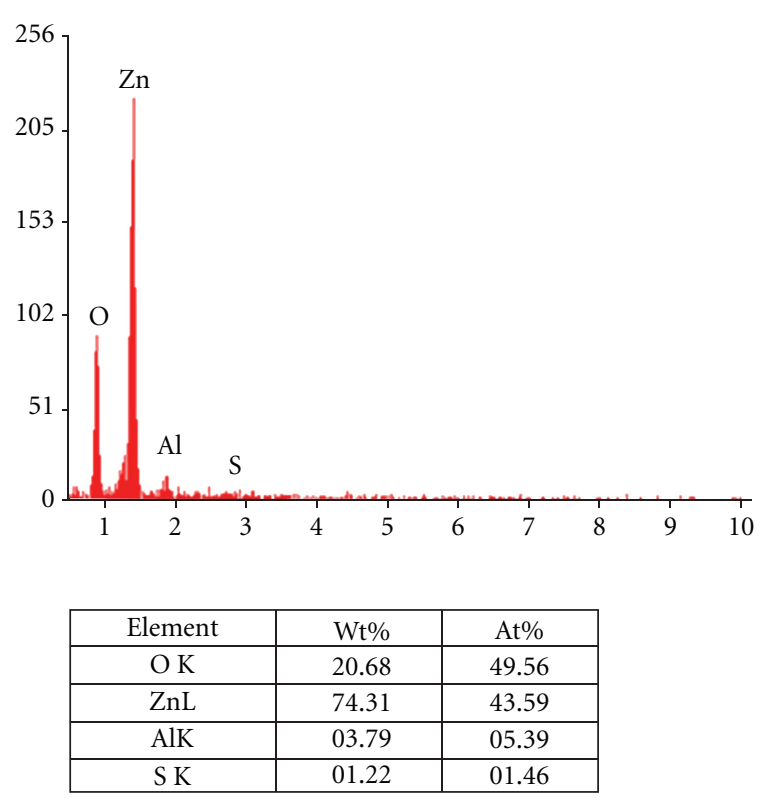

(b)

FIGURE 7: (a) SEM image and (b) EDX spectrum of disklike particles.

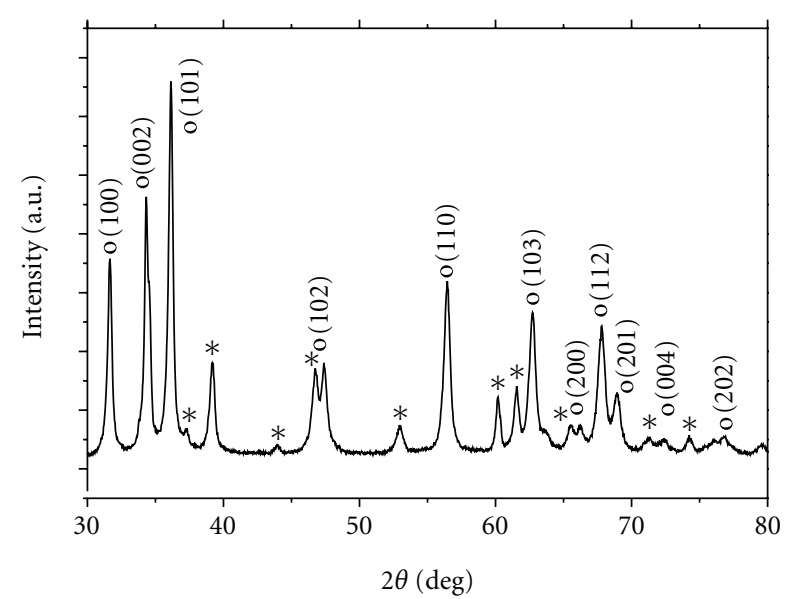

o $\mathrm{ZnO}$

* $\mathrm{Al}_{2} \mathrm{O}_{3}$

FIGURE 8: XRD diffractogram of disklike particles.

$\{100\}$ plane had a lower surface energies than (001) plane. Therefore, $\{100\}$ plane was more stable than (001) plane. The schematic diagram of disklike and ringlike particles formation is proposed in Figure 9.

3.2. Photoluminescence Property of $\mathrm{ZnO}$ Particles. Figure 10 shows the photoluminescence (PL) spectra of disclike, rodlike, and ricelike $\mathrm{ZnO}$ particles. Both near-band-edge emission (NBE, $389 \mathrm{~nm}$ ) and a broad green emission (centered at $572 \mathrm{~nm}$ ) are observed from all the samples. This broad green emission is commonly referred to a deep level or trapstate emission attributed to the singly ionized oxygen vacancy

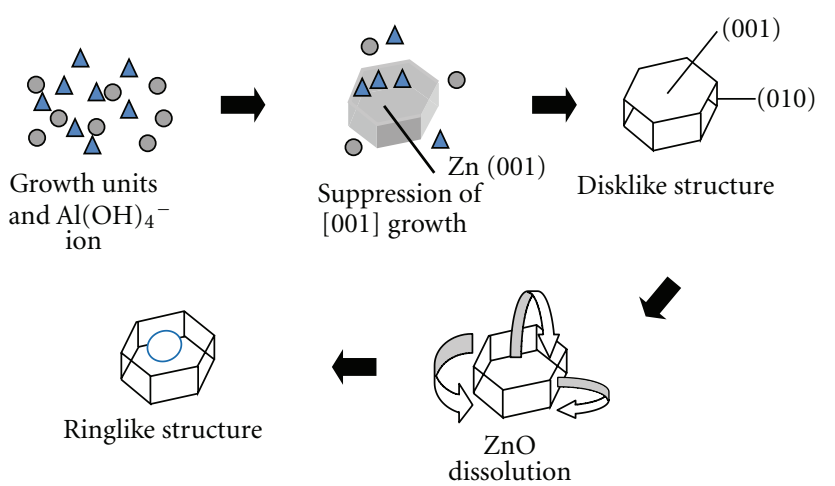

FIGURE 9: Schematic diagram of formation of disklike and ringlike $\mathrm{ZnO}$ particles.

[23]. It has also been reported by Vanheusden et al. that free-carrier depletion at the particle surface, and its effect on the ionization state of the oxygen vacancy, can strongly impact the green emission intensity [24]. Thus, it might be deduced that different morphologies of $\mathrm{ZnO}$ particles, which are different in term of atomic packing density and arrangement of $\mathrm{Zn}$ and $\mathrm{O}$ atoms, may lead to different surface depletion when exposed to air. The surface depletion in the disclike $\mathrm{ZnO}$ particles may be less than in the other morphologies, which might be attributed to the decreasing trend at $572 \mathrm{~nm}$ in Figure 10. Nevertheless, the strongest UV and green emission emitted from flower-like particles indicates that the amount of photogenerated electrons and holes are the largest. A large amount of photogenerated electrons and holes is needed to improve the efficiency of 


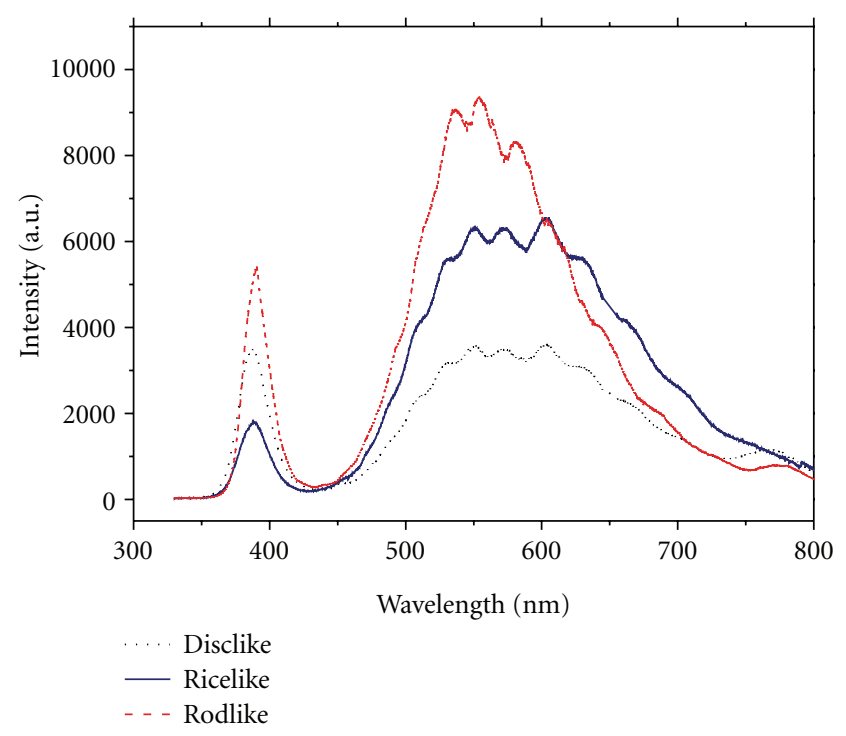

Figure 10: Room temperature photoluminescence spectra of $\mathrm{ZnO}$ particles with different morphology.

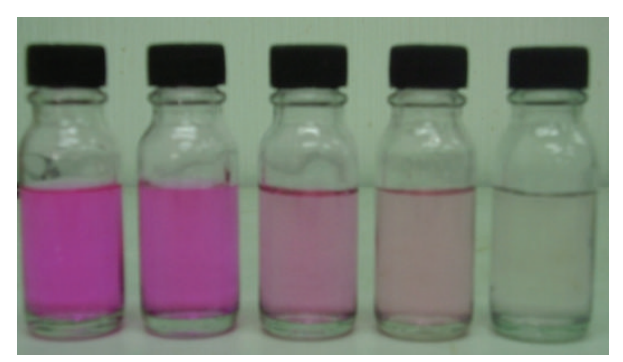

Figure 11: Degradation of $\mathrm{RhB}$ by rodlike $\mathrm{ZnO}$ particles when exposed to UV radiation for $0 \mathrm{~min}, 20 \mathrm{~min}, 40 \mathrm{~min}, 60 \mathrm{~min}$, and $80 \mathrm{~min}$.

$\mathrm{RhB}$ degradation. In addition, the low ratio of NBE/green emission indicates that the crystal quality of samples is poor as they contain many crystal defects.

3.3. Photocatalytic Study of $\mathrm{ZnO}$ Particles. To evaluate the effectiveness of $\mathrm{ZnO}$ particles with different morphologies as photocatalyst, RhB solution was used as a model compound. The mixture of $\mathrm{RhB}$ solution with $\mathrm{ZnO}$ particles with specific morphology was exposed to UV light $(254 \mathrm{~nm})$. Figure 11 shows the degradation of $\mathrm{RhB}$ solution over a period of time using rodlike $\mathrm{ZnO}$ particles as photocatalyst. The color of $\mathrm{RhB}$ slowly faded when exposed to UV radiation for $0 \mathrm{~min}$, $20 \mathrm{~min}, 40 \mathrm{~min}, 60 \mathrm{~min}$, and $80 \mathrm{~min}$.

The photodegradation efficiency of $\mathrm{ZnO}$ particles (ricelike, rodlike, and disklike) were studied by monitoring the UV-Vis absorbance spectra of $\mathrm{RhB}$ at maximum peak of $553 \mathrm{~nm}$ as shown in Figure 12. Figure 12(a) shows the absorption spectra of photocatalytically degraded $\mathrm{RhB}$ aqueous solutions in the presence of ricelike $\mathrm{ZnO}$ particles during different UV irritation times. The absorbance peak of RhB significantly decreased to 0.050 after $60 \mathrm{~min}$ of UV irritation, then continued down to 0.039 of the initial absorbance (1.084) upon prolonging the irritation time to $80 \mathrm{~min}$.
Figure 12(b) shows the absorption spectra of photocatalytically degraded $\mathrm{RhB}$ aqueous solutions in the presence of rodlike $\mathrm{ZnO}$ particles during different $\mathrm{UV}$ irritation times. The absorbance peak of $\mathrm{RhB}$ significantly decreased to 0.0210 after $60 \mathrm{~min}$ of UV irritation and then down to 0.006 upon prolonging the irritation time to $80 \mathrm{~min}$. During the degradation of $\mathrm{RhB}$ dyes over disklike $\mathrm{ZnO}$ particles (Figure 12(c)), the absorbance peak of $\mathrm{RhB}$ decreased to 0.231 after 60 min of UV irritation and then continued down to 0.161 upon prolonging the irritation time to $80 \mathrm{~min}$.

Figure 13 shows the comparison between the photodegradation of $\mathrm{RhB}$ with and without $\mathrm{ZnO}$ particles. Under UV-light irradiation, but in the absence of $\mathrm{ZnO}$ particles, the absorbance of $\mathrm{RhB}$ changed little (2.98\%) after irradiation. This indicates that the photo-induced selfsensitized photolysis of RhB can be neglected. However, the photodegradation was enhanced when ricelike, rodlike, and disklike $\mathrm{ZnO}$ particles were added as catalysts. The absorbance of $\mathrm{RhB}$ aqueous solutions diminished gradually with the increasing exposure time in the presence of $\mathrm{ZnO}$ particles. The photodegradation efficiency of ricelike, rodlike, and disklike $\mathrm{ZnO}$ particles can be deduced from Figure 13. The residual absorbance of RhB at $80 \mathrm{~min}$ UV irritation in the presence of ricelike, rodlike, and disklike $\mathrm{ZnO}$ particles were $0.006,0.039$, and 0.161 , respectively. Thus, rodlike $\mathrm{ZnO}$ particles were the most effective in degrading $\mathrm{RhB}$, followed by ricelike and disklike $\mathrm{ZnO}$ particles.

When the absorbance data are plotted as in $\ln \left(\mathrm{A}_{o} / \mathrm{A}\right)$ of the time-dependent normalized dye concentrations (which is the ratio between the initial concentration and the concentration upon reaction) in Figure 14, linear plots are obtained. This indicates that the decomposition of $\mathrm{RhB}$ follows a first order kinetics regardless the morphology of $\mathrm{ZnO}$ particles. The rate constant of rodlike $\mathrm{ZnO}$ particles is the highest, that is, $0.06329 \mathrm{~min}^{-1}$ (std. error: 0.00236, R-square: $0.99311)$, followed by ricelike particles $\left(0.04317 \mathrm{~min}^{-1}\right.$, std. error: 0.00323 , R-square: 0.97266 ) and disklike particles (0.02448 $\mathrm{min}^{-1}$, std. error: 0.00076, R-square: 0.99514). The highest rate constant of rodlike $\mathrm{ZnO}$ particles could be due to the highest surface area to volume ratio. The surface area to volume ratio for rodlike $\mathrm{ZnO}$ particles was $0.030 \mathrm{~nm}^{-1}$ whereas the ricelike $\mathrm{ZnO}$ particles was $0.017 \mathrm{~nm}^{-1}$. A larger surface area can provide more photocatalytic reaction centers for the absorption of reactant molecules. In addition, a larger surface area is also effective for UV light adsorption and thus generates more electrons and holes [25]. This correlates with the observation of PL result in Figure 10 where the rodlike $\mathrm{ZnO}$ particles produced strongest UV and green emission, followed by ricelike and disklike particles. The higher the number of carriers, the better the photocatalyst is. Thus, a better photocatalytic activity for $\mathrm{ZnO}$ nanorods is achieved as a result of enhanced absorption capacity.

Among the three different types of $\mathrm{ZnO}$ particles, disklike $\mathrm{ZnO}$ particles appeared to be more inferior compared to rodlike and ricelike $\mathrm{ZnO}$ particles. This may be due to the presence of ringlike $\mathrm{ZnO}$ particles. The (001) plane of ringlike $\mathrm{ZnO}$ particles was removed during the dissolution of $\mathrm{ZnO}$. Therefore, less surface area will be exposed to UV 


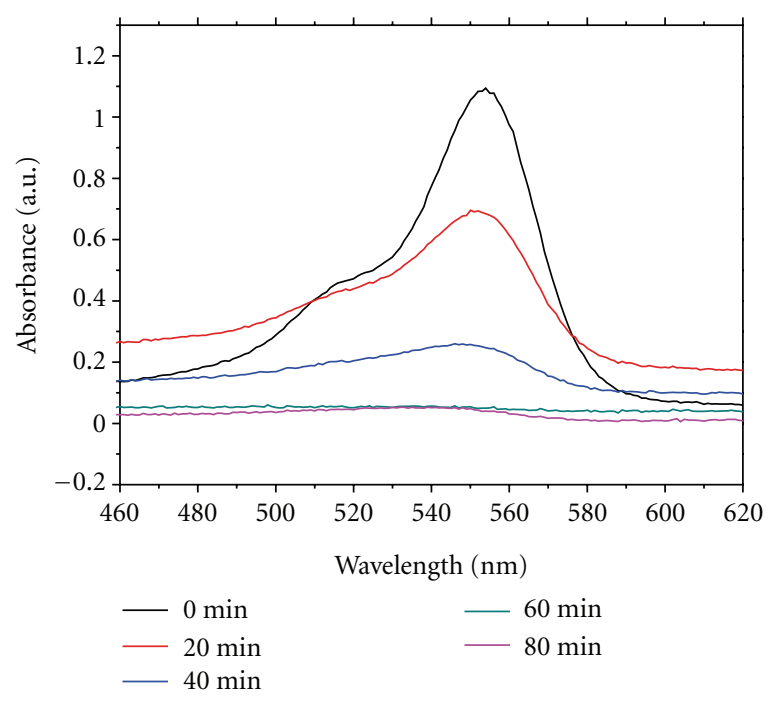

(a)

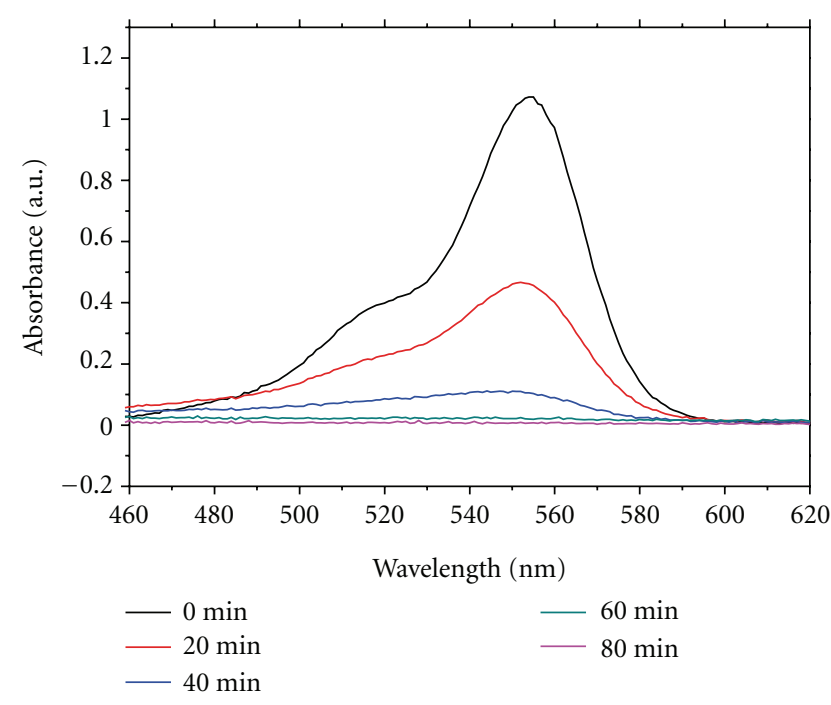

(b)

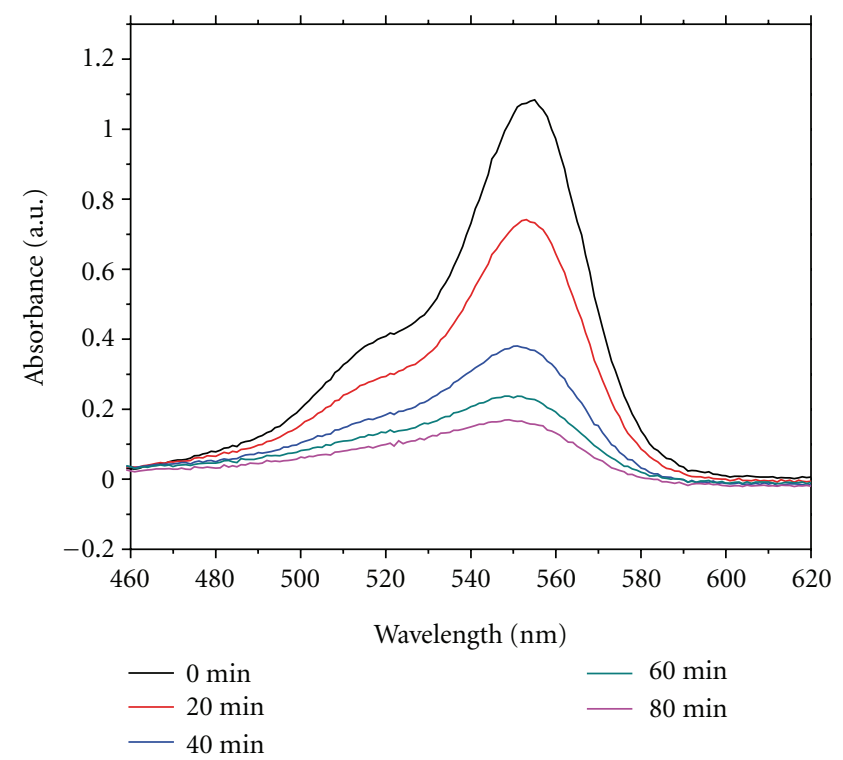

(c)

FIGURE 12: Absorbance spectra of Rhodamine B aqueous solutions with different ZnO particles after UV irradiation with different time, (a) ricelike, (b) rodlike and (c) disklike $\mathrm{ZnO}$ particles.

adsorption. Besides, this may be also due to the presence of $\mathrm{Al}$ element as reported in the EDX analysis. The $\mathrm{Al}$ contamination adhered to the exposed plane of disklike $\mathrm{ZnO}$ particles may deter the UV adsorption. Hence, the photocatalytic performance of disklike $\mathrm{ZnO}$ particles was affected.

The degradation of $\mathrm{RhB}$ solution by $\mathrm{ZnO}$ particles could be explained by mechanism below $[25,26]$. When $\mathrm{ZnO}$ particles were illuminated by UV light with energy greater than the band gap energy, the conduction-band electrons $\left(e_{\mathrm{CB}}^{-}\right)$and valence-band holes $\left(h_{\mathrm{VB}}^{+}\right)$were generated on the surfaces of $\mathrm{ZnO}$ particles as shown in (10). Holes could react with water adhering to the surfaces of $\mathrm{ZnO}$ particles to form highly reactive hydroxyl radicals $\left({ }^{\bullet} \mathrm{OH}\right)$ as in (11).
Meanwhile, oxygen acted as an electron acceptor by forming a superoxide radical anion $\left(\mathrm{O}_{2}^{--}\right)$as in (12). Rhodamine B was believed to be destroyed through direct oxidation by the - $\mathrm{OH}$ radicals and $\mathrm{O}_{2}^{--}$radicals as shown in (13),

$$
\begin{gathered}
\mathrm{ZnO}+\mathrm{hv}(\mathrm{UV}) \longrightarrow e_{\mathrm{CB}}^{-}+h_{\mathrm{VB}}^{+} \\
h_{\mathrm{VB}}^{+}+\mathrm{H}_{2} \mathrm{O} \longrightarrow \mathrm{H}^{+}+{ }^{\cdot} \mathrm{OH} \\
e_{\mathrm{CB}}^{-}+\mathrm{O}_{2} \longrightarrow \mathrm{O}_{2}^{\bullet-}
\end{gathered}
$$

$$
\mathrm{O}_{2}^{--}+\cdot \mathrm{OH}+\text { dye } \longrightarrow \text { degraded product }
$$




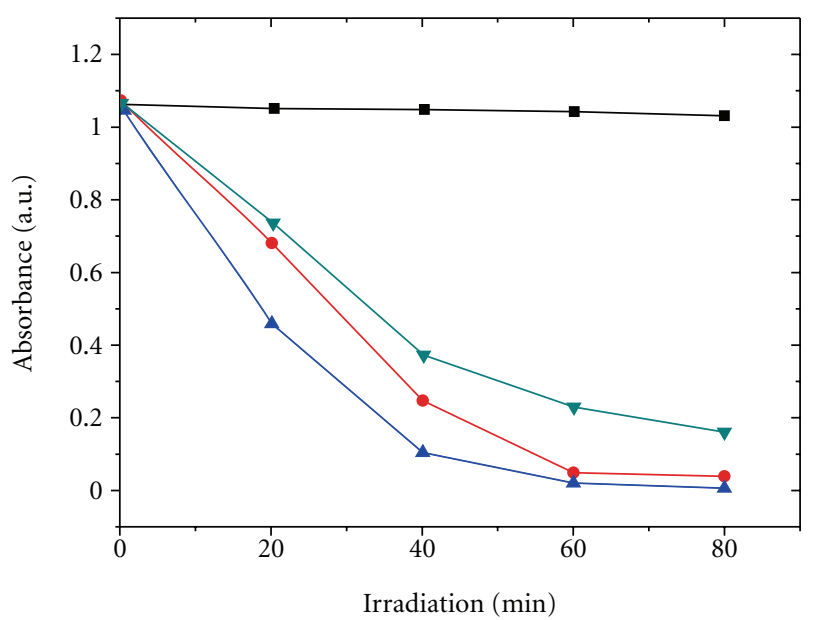

$\begin{array}{ll}\text { Wavelength }(553 \mathrm{~nm}) & \\ \rightarrow \text { Blank } & \rightarrow \text { Rod } \\ \rightarrow \text { Rice } & \rightarrow \text { Disk }\end{array}$

FIgURE 13: Comparative studies of the photocatalytic activity of ricelike, rodlike and disklike $\mathrm{ZnO}$ particles.

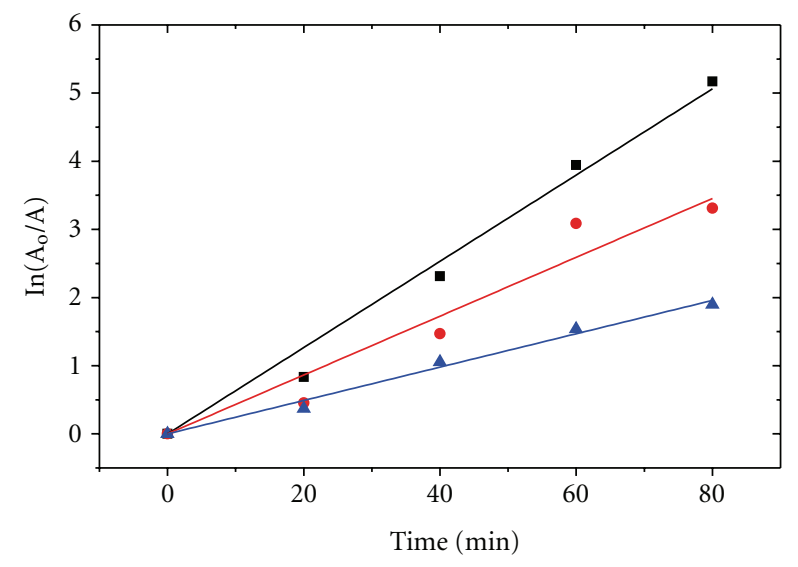

- Rodlike nanoparticles

- Ricelike nanoparticles

A Disclike nanoparticles

\begin{tabular}{|c|c|c|c|}
\hline & Rodlike & Ricelike & Disclike \\
\hline Slope & 0.06329 & 0.04317 & 0.02448 \\
\hline St. error & 0.00236 & 0.00323 & $7.65 \mathrm{E}-04$ \\
\hline$R$-square & 0.99311 & 0.97266 & 0.99514 \\
\hline
\end{tabular}

Figure 14: Degradation of RhB by $\mathrm{ZnO}$ particles with different morphologies.

\section{Conclusions}

$\mathrm{ZnO}$ particles have been successfully synthesized using zinc acetate dehydrate $\left(\mathrm{Zn}\left(\mathrm{CH}_{3} \mathrm{COO}\right)_{2} \cdot 2 \mathrm{H}_{2} \mathrm{O}\right)$ and ammonia $\left(\mathrm{NH}_{4} \mathrm{OH}\right)$ solution as precursors via sol-gel approach. By carefully controlling the process window, various morphologies of $\mathrm{ZnO}$ particles such as ricelike, rodlike, conelike, flower-like, and disklike could be produced. In the photocatalytic study, rodlike $\mathrm{ZnO}$ particles showed the best photocatalytic efficiency, followed by ricelike and disklike
$\mathrm{ZnO}$ particles. This may be due to a larger surface area to volume ratio of rodlike $\mathrm{ZnO}$ particles. On the other hand, disklike $\mathrm{ZnO}$ particles performed poorly for the degradation of $\mathrm{RhB}$. This may be attributed to the presence of ringlike $\mathrm{ZnO}$ particles and/or contamination of $\mathrm{Al}^{3+}$ ions, contributed from the aluminium sulphate solution (complexing agent).

\section{Acknowledgments}

This paper was financially supported by Fundamental Research Grant Scheme (FRGS, 203/PBAHAN/6071210), Ministry of Higher Education, Malaysia. The authors would like to thank Professor Chongxin Shan for his helpful advice in this project.

\section{References}

[1] A. Sugunan and J. Dutta, "Pollution treatment, remediation and sensing," Nanotechnology, vol. 2, pp. 125-147, 2008.

[2] F. D. Mai, C. C. Chen, J. L. Chen, and S. C. Liu, "Photodegradation of methyl green using visible irradiation in $\mathrm{ZnO}$ suspensions. Determination of the reaction pathway and identification of intermediates by a high-performance liquid chromatography-photodiode array-electrospray ionizationmass spectrometry method," Journal of Chromatography A, vol. 1189, no. 1-2, pp. 355-365, 2008.

[3] J. J. Vora, S. K. Chauhan, K. C. Parmar, S. B. Vasava, S. Sharma, and L. S. Bhutadiya, "Kinetic study of application of $\mathrm{ZnO}$ as a photocatalyst in heterogeneous medium," E-Journal of Chemistry, vol. 6, no. 2, pp. 531-536, 2009.

[4] S. Liu, C. Li, J. Yu, and Q. Xiang, "Improved visible-light photocatalytic activity of porous carbon self-doped $\mathrm{ZnO}$ nanosheet-assembled flowers," CrystEngComm, vol. 13, no. 7, pp. 2533-2541, 2011.

[5] F. Barka-Bouaifel, B. Sieber, N. Bezzi et al., "Synthesis and photocatalytic activity of iodine-doped $\mathrm{ZnO}$ nanoflowers," Journal of Materials Chemistry, vol. 21, no. 29, pp. 1098210989, 2011.

[6] M. A. Kanjwal, N. A. M. Barakat, F. A. Sheikh, S. J. Park, and H. Y. Kim, "Photocatalytic activity of $\mathrm{ZnO}-\mathrm{TiO}_{2}$ hierarchical nanostructure prepared by combined electrospinning and hydrothermal techniques," Macromolecular Research, vol. 18, no. 3, pp. 233-240, 2010.

[7] K. Byrappa, A. K. Subramani, S. Ananda, K. M. Lokanatha Rai, R. Dinesh, and M. Yoshimura, "Photocatalytic degradation of rhodamine B dye using hydrothermally synthesized $\mathrm{ZnO}$," Bulletin of Materials Science, vol. 29, no. 5, pp. 433-438, 2006.

[8] G. Wang, D. Chen, H. Zhang, J. Z. Zhang, and J. Li, "Tunable photocurrent spectrum in well-oriented zinc oxide nanorod arrays with enhanced photocatalytic activity," Journal of Physical Chemistry C, vol. 112, no. 24, pp. 8850-8855, 2008.

[9] C. C. Chen, "Degradation pathways of ethyl violet by photocatalytic reaction with $\mathrm{ZnO}$ dispersions," Journal of Molecular Catalysis A, vol. 264, no. 1-2, pp. 82-92, 2007.

[10] K. Byrappa, A. K. Subramani, S. Ananda, K. M. Lokanatha Rai, R. Dinesh, and M. Yoshimura, "Photocatalytic degradation of rhodamine B dye using hydrothermally synthesized $\mathrm{ZnO}$," Bulletin of Materials Science, vol. 29, no. 5, pp. 433-438, 2006.

[11] J. Zhao and L. Wang, "Degradation of rhodamine B in aqueous solution by the UV/ZnO photocatalytic process," in Proceedings of the International Conference on Materials for 
Renewable Energy \& Environment (ICMREE '11), pp. 139714000, Shanghai, China, May 2011.

[12] F. Barka-Bouaifel, B. Sieber, N. Bezzi et al., "Synthesis and photocatalytic activity of iodine-doped $\mathrm{ZnO}$ nanoflowers," Journal of Materials Chemistry, vol. 21, no. 29, pp. 1098210989, 2011.

[13] M. C. M. Alvim Ferraz, S. Möser, and M. Tonhäeuser, "Control of atmospheric emissions of volatile organic compounds using impregnated active carbons," Fuel, vol. 78, no. 13, pp. 1567$1573,1999$.

[14] C. Wu, X. Qiao, J. Chen, H. Wang, F. Tan, and S. Li, "A novel chemical route to prepare $\mathrm{ZnO}$ nanoparticles," Materials Letters, vol. 60, no. 15, pp. 1828-1832, 2006.

[15] Y. Masuda, N. Kinoshita, and K. Koumoto, "Morphology control of $\mathrm{ZnO}$ crystalline particles in aqueous solution," Electrochimica Acta, vol. 53, no. 1, pp. 171-174, 2007.

[16] D. Vernardou, G. Kenanakis, S. Couris, E. Koudoumas, E. Kymakis, and N. Katsarakis, "pH effect on the morphology of $\mathrm{ZnO}$ nanostructures grown with aqueous chemical growth," Thin Solid Films, vol. 515, no. 24, pp. 8764-8767, 2007.

[17] J. Zhang, L. Sun, J. Yin, H. Su, C. Liao, and C. Yan, "Control of $\mathrm{ZnO}$ morphology via a simple solution route," Chemistry of Materials, vol. 14, no. 10, pp. 4172-4177, 2002.

[18] S. Cho, S. H. Jung, and K. H. Lee, "Morphology-controlled growth of $\mathrm{ZnO}$ nanostructures using microwave irradiation: from basic to complex structures," Journal of Physical Chemistry C, vol. 112, no. 33, pp. 12769-12776, 2008.

[19] H. Xu, H. Wang, Y. Zhang et al., "Hydrothermal synthesis of zinc oxide powders with controllable morphology," Ceramics International, vol. 30, no. 1, pp. 93-97, 2004.

[20] Y. Jiang, Y. Sheng, X. Lan et al., "Mechanism and growth of flexible $\mathrm{ZnO}$ nanostructure arrays in a facile controlled way," Journal of Nanomaterials, vol. 2011, Article ID 473629, 12 pages, 2011.

[21] Y. Jiang, X. Wu, W. Zhang, L. Ni, and Y. Sun, "Evolution of $\mathrm{ZnO}$ architecture on a nanoporous $\mathrm{TiO}_{2}$ film by a hydrothermal method and the photoelectrochemical performance," Journal of Semiconductors, vol. 32, no. 3, 2011.

[22] C. Ye, Y. Bando, G. Shen, and D. Golberg, "Thicknessdependent photocatalytic performance of $\mathrm{ZnO}$ nanoplatelets," Journal of Physical Chemistry B, vol. 110, no. 31, pp. 1514615151, 2006.

[23] K. Vanheusden, W. L. Warren, C. H. Seager, D. R. Tallant, J. A. Voigt, and B. E. Gnade, "Mechanisms behind green photoluminescence in $\mathrm{ZnO}$ phosphor powders," Journal of Applied Physics, vol. 79, no. 10, pp. 7983-7990, 1996.

[24] K. Vanheusden, C. H. Seager, W. L. Warren, D. R. Tallant, and J. A. Voigt, "Correlation between photoluminescence and oxygen vacancies in $\mathrm{ZnO}$ phosphors," Applied Physics Letters, vol. 68, no. 3, pp. 403-405, 1996.

[25] L. Wang, L. Chang, B. Zhao, Z. Yuan, G. Shao, and W. Zheng, "Systematic investigation on morphologies, forming mechanism, photocatalytic and photoluminescent properties of $\mathrm{ZnO}$ nanostructures constructed in ionic liquids," Inorganic Chemistry, vol. 47, no. 5, pp. 1443-1452, 2008.

[26] J. H. Zeng, B. B. Jin, and Y. F. Wang, "Facet enhanced photocatalytic effect with uniform single-crystalline zinc oxide nanodisks," Chemical Physics Letters, vol. 472, no. 1-3, pp. 9095, 2009. 


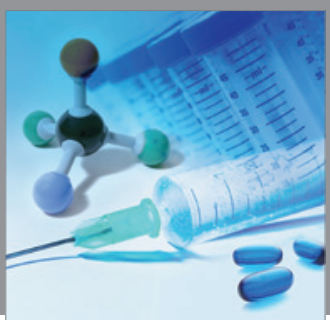

International Journal of

Medicinal Chemistry

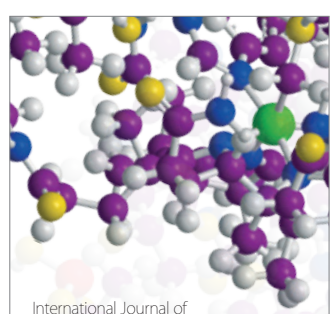

Carbohydrate Chemistry

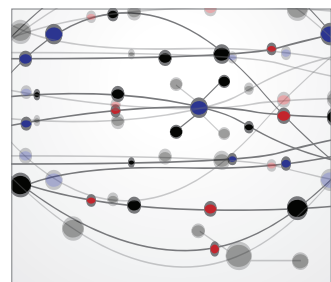

The Scientific World Journal
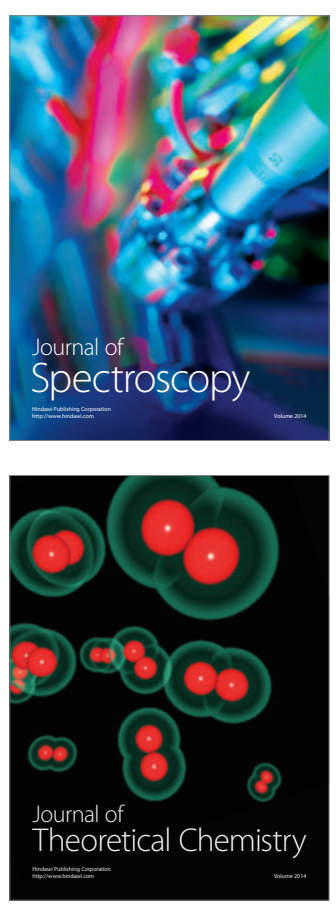
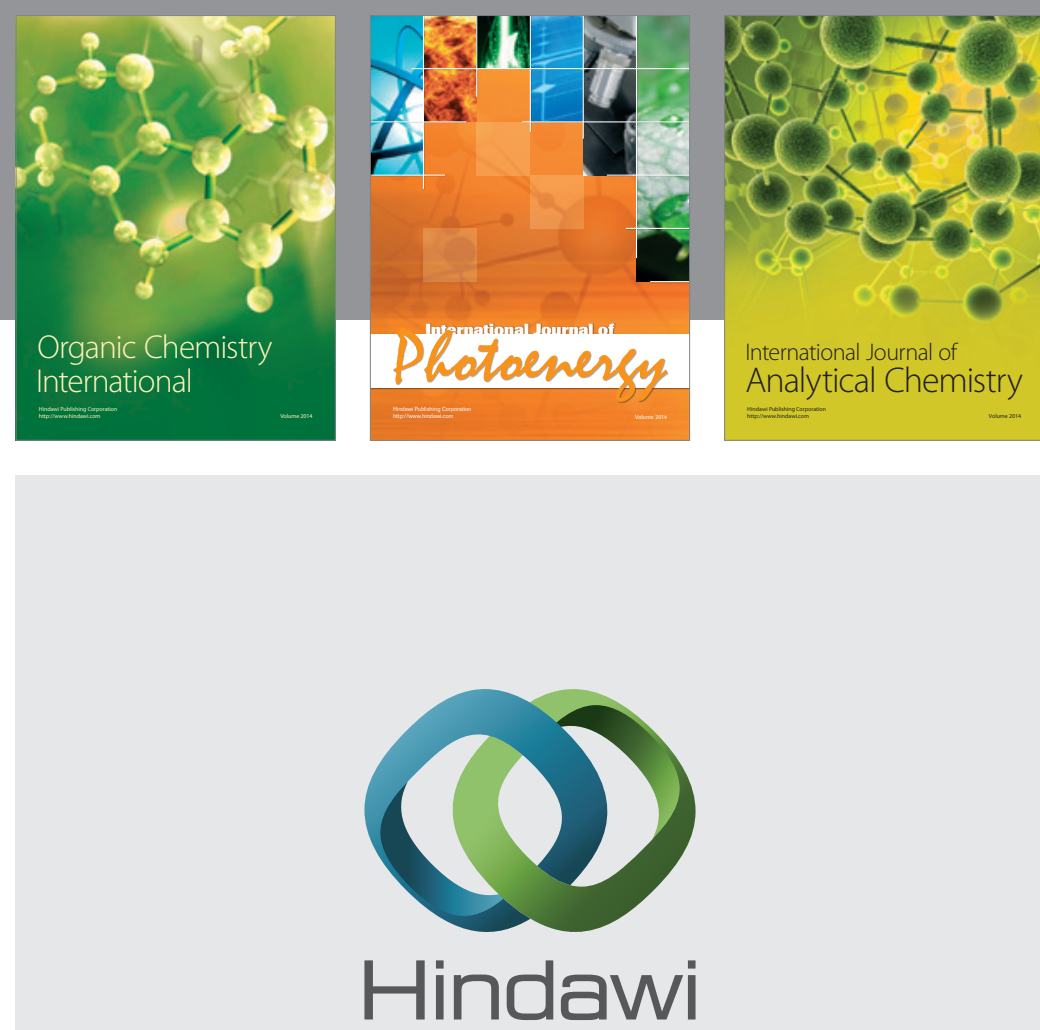

Submit your manuscripts at

http://www.hindawi.com
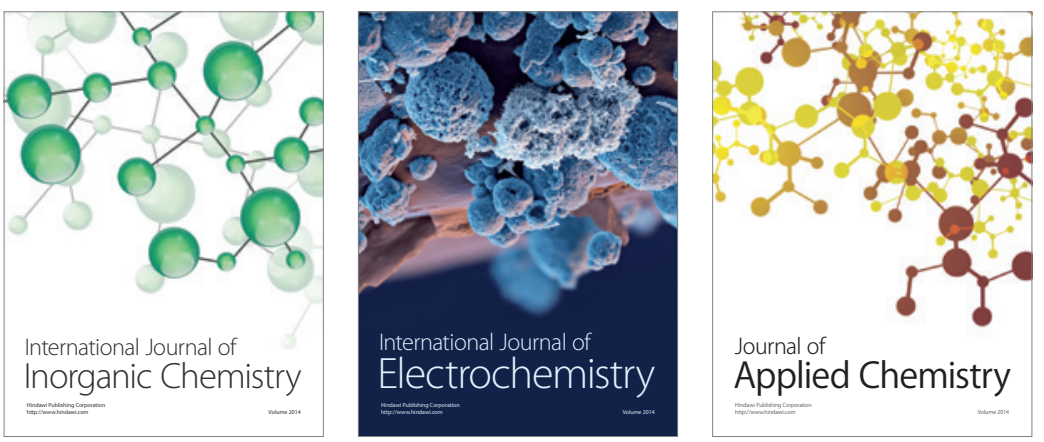

Journal of

Applied Chemistry
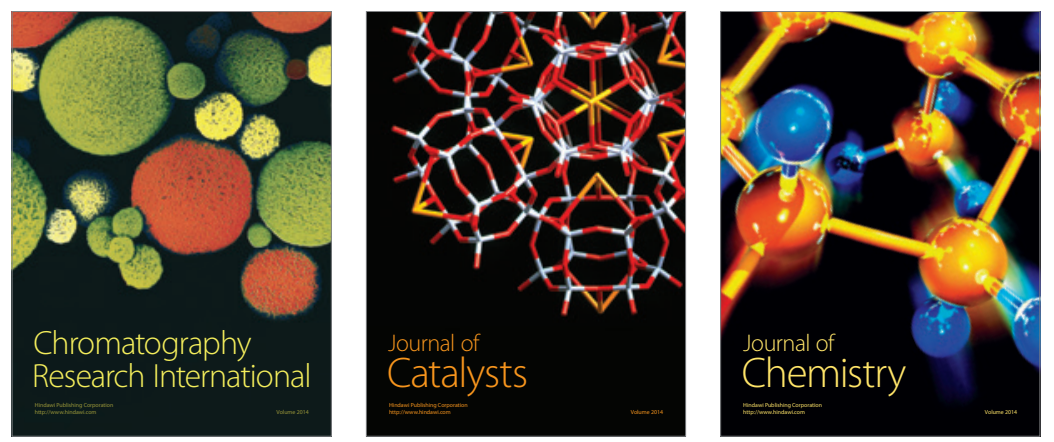
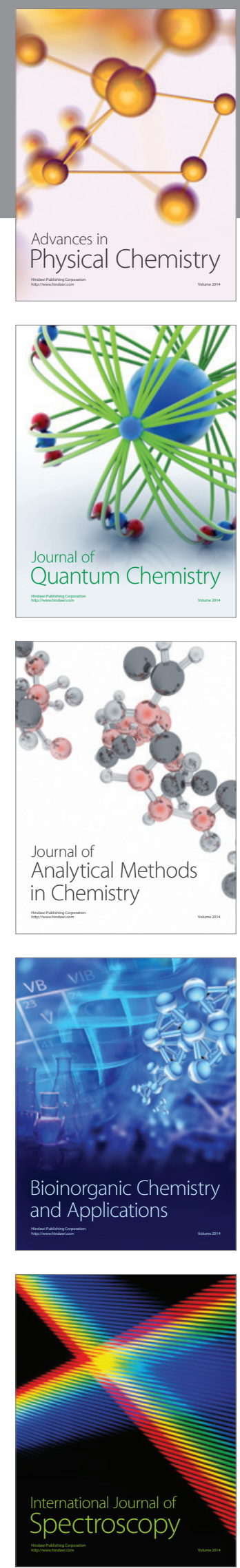